\title{
DOI: https://doi.org/10.24297/jac.v18i.8964
}

\author{
Determination of Pitavastatin Calcium by Analytical Spectrophotometry \\ Saad Antakli', Leon Nejem ${ }^{2}$ and Ahmad Kullah ${ }^{3}$ \\ 1,2,3 Department of Chemistry, Faculty of Science, University of Aleppo, Syria
}

\begin{abstract}
;
Simple and rapid spectrophotometric method for the quantitative analysis of Pitavastatin calcium (PTV) in raw material and tablets pharmaceutical formulation has been described. The method is based on the formation of yellow ion-pair complex between Pitavastatin calcium and Bromocresol purple (BCP) in chloroform medium.
\end{abstract}

Different parameters affecting the reaction such as: effect of solvents, stability, reagent concentration, correlation ratio, etc. were optimized. The formed complex was quantified spectrophotometrically at absorption maximum $405 \mathrm{~nm}$. Linearity range was $2.20-35.23 \mu \mathrm{g} / \mathrm{mL}$, regression analysis showed a good correlation coefficient $R^{2}=0.9991$. The limit of detection (LOD) and limit of quantification (LOQ) were to be $0.367 \mu \mathrm{g} / \mathrm{mL}$ and $1.112 \mu \mathrm{g} / \mathrm{mL}$ respectively. The average percent recovery was found to be (100.62 - 101.14) \% for Pitavastatin Calcium. This study was applied on Syrian pharmaceutical trademark: (PAVACRIUM $4 \&$ Londalop). The method was successfully applied for the determination of Pitavastatin calcium in tablets pharmaceutical formulation.

The proposed method is simple, direct, sensitive and do not require any extraction process. Thus, this method could be readily applicable for the quality control and routine analysis.

KEYWORDS: Pitavastatin calcium, Bromocresol purple, Spectrophotometric.

\section{INTRODUCTION}

Pitavastatin is the first synthetic 3-hydroxy-3-methylglutaryl coenzyme A (HMG-CoA) reductase inhibitor which was discovered in Japan. It is chemically monocalcium bis (3R,5S,6E)-7-(2-cyclopropyl-4-[4-fluorophenyl]-3quinolyl-3,5-dihydroxy-6-heptenoate), used as the calcium salt in the treatment of hyperlipidaemia and can reduce the risk of cardiovascular diseases in everyday medical practice. Based on the preclinical findings, Pitavastatin significantly decreased the serum levels of total cholesterol and low-density lipoprotein cholesterol at doses of $1 \mathrm{mg} /$ day or more. It also significantly decreased the serum levels of triglycerides within this dose range. There was no dose-dependence of the incidence of adverse reactions to Pitavastatin. One other characteristic of the agent is that Pitavastatin is minimally metabolized by the cytochrome P450 isozymes; it undergoes glucuronidation and is converted to the inactive lactone form, therefore, the incidence of any drug interactions is reduced. Due to the promising results observed in clinical trials, it has the potential to be an excellent addition to the worldwide lipid management market ${ }^{1-5}$.

The estimation of Pitavastatin calcium (PTV) from pharmaceutical formulations has been determining by several analytical methods. These include spectrophotometric method, based on ability of potassium permanganate to oxidize Pitavastatin in acidic medium 6 . UV spectrophotometric methods for the determination of Pitavastatin calcium $^{7,8}$, Color reactions for spectrophotometric determination of Pitavastatin calcium ${ }^{9,10 .}$. Spectrofluorometric method is based on measuring the native fluorescence of the drugs at their optimum excitation and emission wavelengths ${ }^{11}$, High performance thin layer chromatography (HPTLC) ${ }^{12,13}$. High performance liquid chromatography (HPLC) ${ }^{14-16}$. Ultra High performance liquid chromatography (UHPLC) method for the selective quantification of Pitavastatin calcium ${ }^{17}$. Reverse-phase high performance liquid chromatography (RP-HPLC) ${ }^{18-20}$. Liquid chromatography-tandem mass spectrometry (LC-MS/MS) ${ }^{21,22}$

Bromocresol purple (BCP) which is a brominated acid dye of the sulfonephthalein series derived from orthocresol that is obtained as a pinkish crystalline powder and is used as an acid-base indicator commonly used as indicator and spectrophotometric reagent. 


\section{MATERIALS AND METHODS}

\section{Apparatus}

A Jasco V-630 UV-VIS spectrophotometer (Japan) with $1 \mathrm{~cm}$ quartz cells. Ultrasonic bath Daihan (China), and stirrer Velp Scientifica (Europe), Sartorius balance, sensitivity $10^{-5} \mathrm{~g}$.

\section{Chemical regents:}

Pitavastatin calcium (PTV): $\mathrm{C}_{50} \mathrm{H}_{46} \mathrm{CaF}_{2} \mathrm{~N}_{2} \mathrm{O}_{8}, \mathrm{Mw}=880.98 \mathrm{~g} / \mathrm{mol}$ from (China), its purity $99.5 \%$. Bromocresol purple (BCP): $\mathrm{C}_{21} \mathrm{H}_{16} \mathrm{Br}_{2} \mathrm{O}_{5} \mathrm{~S}, \mathrm{M}_{\mathrm{W}}=540.22 \mathrm{~g} / \mathrm{mol}$ from Merck (Germany). Methanol and Chloroform from Merck (Germany).

\section{STANDARD PREPARATION}

\section{Pitavastatin calcium stock solution}

Stock solution $1 \times 10^{-3} \mathrm{M}$ of Pitavastatin calcium ( $\mathrm{MW}=880.98 \mathrm{~g} / \mathrm{mol}$ ) was prepared by dissolving $8.85 \mathrm{mg}$ of raw material equivalent to $8.894 \mathrm{mg}$ (by taken the purity in consideration) in volumetric flask $10 \mathrm{~mL}$ with $2 \mathrm{~mL}$ methanol and completed to volume with Chloroform to give concentration $1 \times 10^{-3} \mathrm{M}$ equivalent to 880.98 $\mu \mathrm{g} / \mathrm{mL}$. The working standard solutions of Pitavastatin calcium were prepared by appropriate dilutions among (25 - 400) $\mu \mathrm{L}$ of $880.98 \mu \mathrm{g} / \mathrm{mL}$ solution in volumetric flasks $10 \mathrm{~mL}$ and added to each one of BCP $10^{-2} \mathrm{M}$ equals to ten times of Pitavastatin calcium concentration, then completed to volume with Chloroform to give concentrations between $(1.10-35.24) \mu \mathrm{g} / \mathrm{mL}$ of Pitavastatin calcium.

\section{Reagent stock solution}

Bromocresol purple $10^{-2} \mathrm{M}$ was prepared by dissolving $270.11 \mathrm{mg}$ of $\mathrm{BCP}(\mathrm{Mw}=540.22 \mathrm{~g} / \mathrm{mol})$ in volumetric flask $50 \mathrm{~mL}$ and completing to volume with Chloroform.

\section{Calibration Curve}

To construct the calibration curve, five standard solutions for each concentration were prepared and the absorbance was measured of each solution five times.

\section{Sample preparation}

Two products were studied :

Twenty tablets from PAVACORIUM 4 and Londalop Syrian products were weighed and finely powdered and an accurate weight equivalent to $4 \mathrm{mg}$ (PTV) was accurately weighed, dissolved in volumetric flask $10 \mathrm{~mL}$ in Methanol, then $1 \mathrm{~mL}$ of the solution was taken to volumetric flask $10 \mathrm{~mL}$ and diluted to volume with Chloroform. $1 \mathrm{~mL}$ of the last solution was taken to volumetric flask $10 \mathrm{~mL}$ and added $1 \mathrm{~mL}$ of Bromocresol purple $10^{-2} \mathrm{M}$, then diluted to volume with Chloroform, equivalent theoretically to $4.0 \mu \mathrm{g} / \mathrm{mL}$ for (PTV).

\section{RESULTS AND DISCUSSION}

Pitavastatin calcium forms with Bromocresol purple at $25 \pm 5^{\circ} \mathrm{C}$ yellow ion-pair complex. The result solution was scanned in the range of wavelengths $300-550 \mathrm{~nm}$ against a blank of BCP solved in chloroform, then measured the absorbance at maximum wavelength $405 \mathrm{~nm}$. We studied all the parameters of the colored result solutions to obtain the optimal conditions.

Fig. 1 shows the complex spectrum between Pitavastatin calcium and Bromocresol purple in Chloroform medium. 


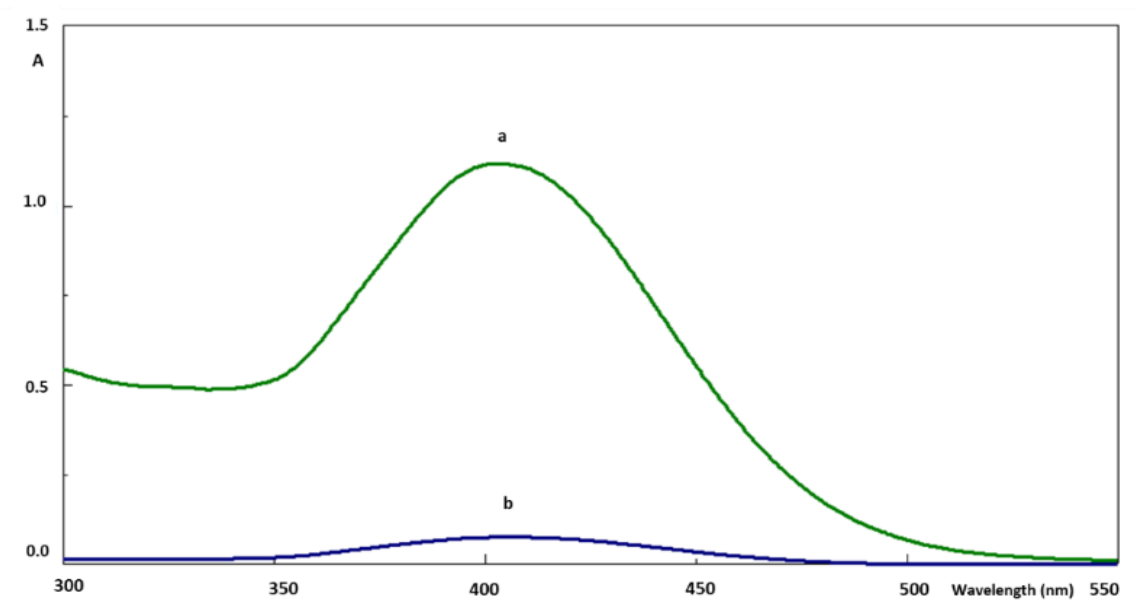

Fig. 1: a- Spectrum of complex PTV-BCP in Chloroform medium, $[\mathrm{PTV}]=2 \times 10^{-5} \mathrm{M}$

b- Spectrum of BCP in Chloroform medium, $[B C P]=2 \times 10^{-4} \mathrm{M}$.

\section{Stability of stock solution}

Time effect on stability standard stock solution of Pitavastatin calcium in Chloroform was studied in three different concentrations $1 \times 10^{-5}, 2 \times 10^{-5}$ and $3 \times 10^{-5} \mathrm{M}$. We did not notice any significant absorption changes within one month.

\section{Effect of reagent concentration}

To study the effect of reagent concentration on the colored complex solution, we made a series of $10 \mathrm{~mL}$ of separated volumetric flasks, by adding $0.25 \mathrm{~mL}$ of Pitavastatin calcium $25 \times 10^{-6} \mathrm{M}$ equivalent to $25 \mu \mathrm{M}$ and added between $(0.0125-0.300 \mathrm{~mL})$ of $(B C P) 1 \times 10^{-2} \mathrm{M}$, equivalent to $(12.5-300 \mu \mathrm{M})$ after completing the volume to $10 \mathrm{~mL}$ by chloroform. The absorbance at $405 \mathrm{~nm}$ for every added (BCP) reagent was measured against the blank of chloroform. It was found that the completed colored complex formation in the best condition was 250 $\mu \mathrm{M}$ of (BCP) equivalent to $0.250 \mathrm{~mL}$ of $(\mathrm{BCP})$ which equal to ten times of Pitavastatin calcium concentration, as it is shown in Fig. 2.

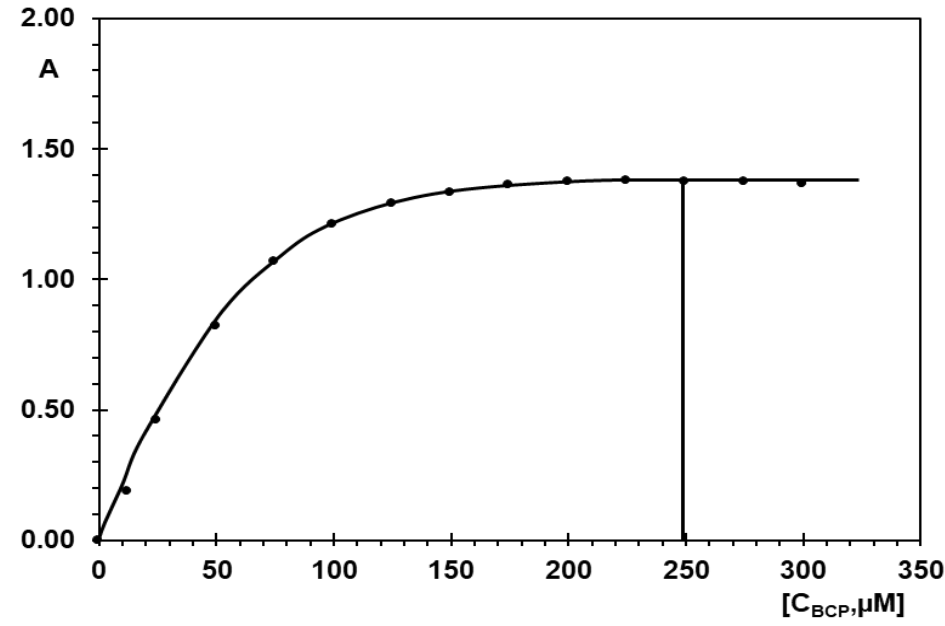

Fig. 2: Effect of reagent concentration.

Pitavastatin Calcium concentration $25 \mu \mathrm{M}$.

\section{Correlation ratios by molecular ratio}

We have prepared a series of complex solutions PTV-BCP in chloroform medium. The concentration of the (BCP) reagent changes within the ratio $\left(0.25 \times 10^{-4}-7.0 \times 10^{-5}\right) \mathrm{M}$ while the concentration of Pitavastatin calcium was constant in each solution and equal to $2.5 \times 10^{-5} \mathrm{M}$. We measured the absorbance values of these solutions at the wavelength of the maximum absorbance $405 \mathrm{~nm}$ (using chloroform as a blank). The absorption changes of 
the molecular ratio of the reagent to the Pitavastatin calcium permitted to measure correlation ratio. We obtained the curve $A=f([B C P] /[P T V])$ shown in Fig. 3 where the correlation ratios are $(1: 1 \& 2: 1)$.

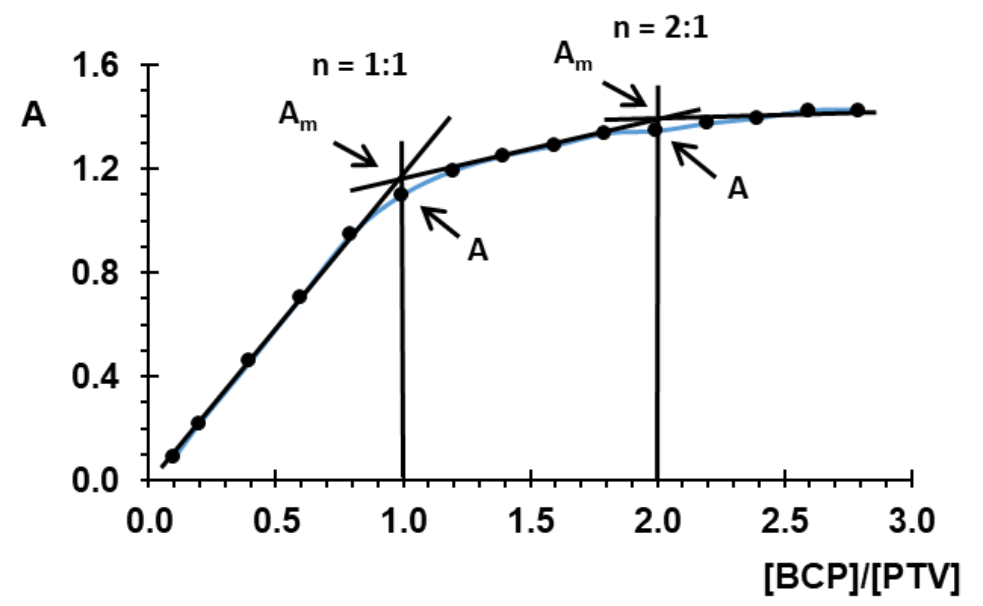

Fig. 3: Correlation molecular ratios (1:1 \& 2:1).

\section{Correlation ratios by continuous variation}

We have prepared a series of complex solutions PTV-BCP in the medium of the Chloroform. The concentration of the reagent and the concentration of Pitavastatin calcium changes in solutions between $(0.5-5) 10^{-5} \mathrm{M}$ where the sum of both concentrations remains constant and equal to $5 \times 10^{-5} \mathrm{M}$.

We measured the absorbance values of these solutions at the wavelength of the maximum absorbance $405 \mathrm{~nm}$ according to the used reagent percentage of the formed complex in terms of molecular fraction of Pitavastatin calcium. We obtained the curve $A=f([B C P] /\{[B C P]+[P T V]\})$, shown in fig. 4, where the correlation ratios are also $(1: 1 \& 2: 1)$.

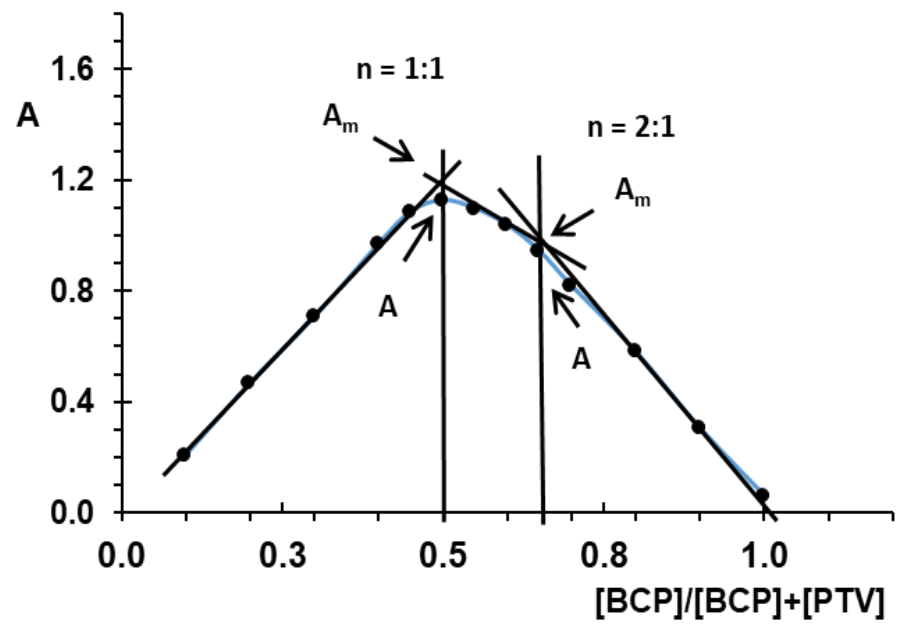

Fig. 4: Correlation ratio by continuous variation $(1: 1 \& 2: 1)$.

\section{Calculation of formation constant for the (PTV:BCP) complex}

The conditional stability constants $(K f)$ of the ion-pair complexes were calculated from molecular ratio and the continuous variation curves.

Data using the following equation ${ }^{23-25}$.

$$
K_{f}=\frac{\mathrm{A} / \mathrm{A}_{\mathrm{m}}}{\left[1-\frac{A}{A_{m}}\right]^{n+2} C_{M}(n)^{n}}
$$


Where $A$ and $A_{m}$ are the absorbance value and the observed maximum absorbance value when all the Pitavastatin calcium is completely associated with Bromocresol purple, respectively. $C_{M}$ is the mole concentration of Pitavastatin calcium at the maximum absorbance and $n$ is the stoichiometry, which dye ion associates with Pitavastatin calcium. The log $K_{f}$ values for PTV-BCP ion-pair, associated at correlation ratio $(1: 1 \& 2: 1)$ by molecular ratio were 8.59 and 13.57 respectively, and by continuous variation were 8.66 and 13.65 respectively, so $\log K_{f}$ average are 8.63 and 13.61 at correlation ratio $(1: 1 \& 2: 1)$ respectively.

\section{METHOD'S VALIDATION}

The validity and suitability of the proposed method was assessed by linearity (evaluated by regression equation), limit of detection (LOD), limit of quantification (LOQ), accuracy (reported as percent \%), precision (reported as RSD \%), robustness, and Sandall's sensitivity.

\section{Linearity}

We studied the linearity of Pitavastatin calcium concentrations at the optimal conditions, where we made a series of $10 \mathrm{~mL}$ of separated volumetric flasks, each one contains concentration of BCP equals to ten times of Pitavastatin calcium concentration, where the variable concentrations of PTV stock solution $1 \times 10^{-3} \mathrm{M}$ and the concentrations of $\mathrm{BCP}$ stock solution $1 \times 10^{-2} \mathrm{M}$, then the volumetric flasks completed to $10 \mathrm{~mL}$ with Chloroform, finally we measured the absorbance at $405 \mathrm{~nm}$ for each concentration against the blank of BCP in chloroform. Fig. 5 presents the complex of Pitavastatin calcium with BCP spectra. The range of linearity was obeyed to Beer's law in concentration $(2.20-35.23) \mu \mathrm{g} / \mathrm{mL}$ and the linearity curve is presented in Fig. 6 .

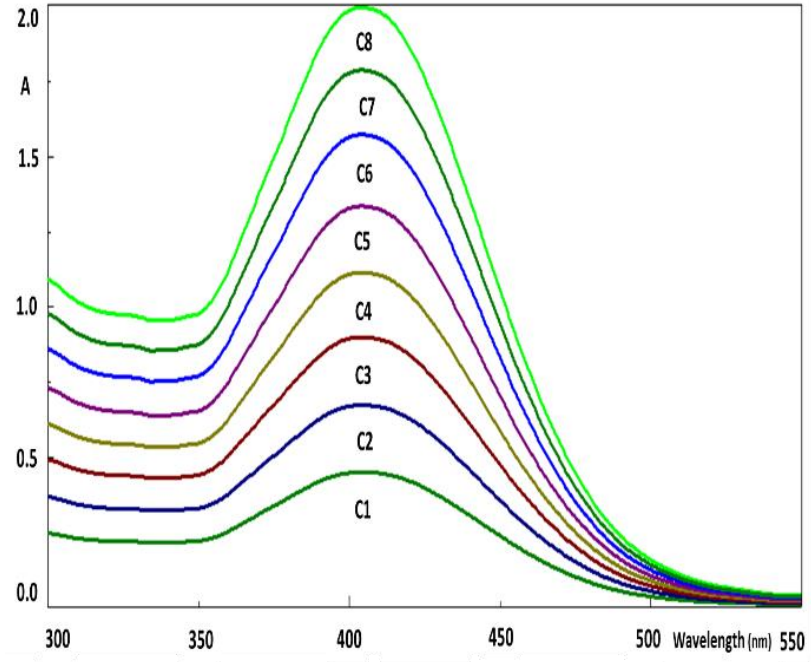

Fig. 5: spectra of (PTV-BCP) complex

for different concentration of ( PTV) :

$\mathrm{C}_{1}: 4.40 \mu \mathrm{g} / \mathrm{mL}, \mathrm{C}_{2}: 8.80 \mu \mathrm{g} / \mathrm{mL}$,

$\mathrm{C}_{3}: 13.21 \mu \mathrm{g} / \mathrm{mL}, \mathrm{C}_{4}: 17.61 \mu \mathrm{g} / \mathrm{mL}$,

$\mathrm{C}_{5}: 22.02 \mu \mathrm{g} / \mathrm{mL}, \mathrm{C}_{6}: 26.42 \mu \mathrm{g} / \mathrm{mL}$,

$\mathrm{C}_{7}: 30.83 \mu \mathrm{g} / \mathrm{mL}, \mathrm{C}_{8}: 35.23 \mu \mathrm{g} / \mathrm{mL}$.

$\mathbf{n}=\mathbf{5}$ for each concentration.

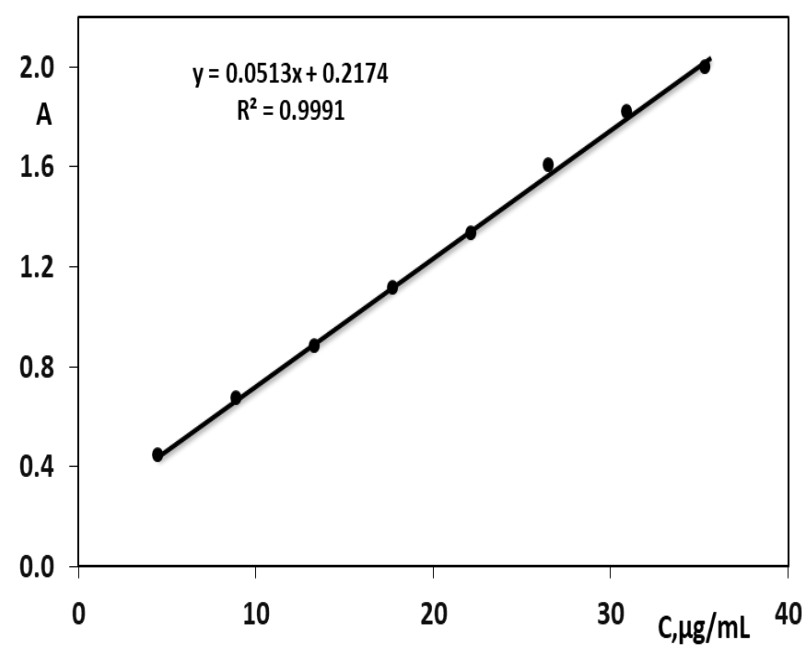

Fig. 6: Calibration curve for (PTV-BCP) complex for different concentration of ( PTV) :

$\mathrm{C}_{1}: 4.40 \mu \mathrm{g} / \mathrm{mL}, \mathrm{C}_{2}: 8.80 \mu \mathrm{g} / \mathrm{mL}$,

$\mathrm{C}_{3}: 13.21 \mu \mathrm{g} / \mathrm{mL}, \mathrm{C}_{4}: 17.61 \mu \mathrm{g} / \mathrm{mL}$,

$\mathrm{C}_{5}: 22.02 \mu \mathrm{g} / \mathrm{mL}, \mathrm{C}_{6}: 26.42 \mu \mathrm{g} / \mathrm{mL}$,

$\mathrm{C}_{7}: 30.83 \mu \mathrm{g} / \mathrm{mL}, \mathrm{C}_{8}: 35.23 \mu \mathrm{g} / \mathrm{mL}$.

$\mathbf{n}=\mathbf{5}$ for each concentration. 


\section{Limit of Detection (LOD) and Limit of Quantification (LOQ)}

In spite of the measurement LOD and LOQ, five concentrations were analyzed in five replicates.

LOD and LOQ for Pitavastatin Calcium were calculated by using the following equations:

$\mathrm{LOD}=\frac{3.3 \times \mathrm{SD}}{\mathrm{m}} ; \mathrm{LOQ}=\frac{10 \times \mathrm{SD}}{\mathrm{m}}$

Where SD, is the standard deviation of $y$ intercepts of regression lines and $m$ is the slope of the calibration curve. The limit of detection (LOD) and limit of quantification (LOQ) were to be $0.367 \mu \mathrm{g} / \mathrm{mL}$ and $1.112 \mu \mathrm{g} / \mathrm{mL}$ respectively.

\section{Accuracy}

To determine the precision and accuracy of the proposed method, five replicates determinations were carried out on five different concentrations of standards (PTV).

The validation results are presented in table 1.

Table 1: Precision and accuracy for determination of Pitavastatin calcium.

\begin{tabular}{|c|c|c|c|c|c|c|}
\hline Sample & $\begin{array}{l}\text { Theoretical } \\
\text { concentration } \\
(\mu \mathrm{g} / \mathrm{mL})\end{array}$ & $\begin{array}{c}\bar{x} \text { Observed } \\
\text { concentration } \\
(\mu \mathrm{g} / \mathrm{mL})\end{array}$ & $\begin{array}{l}S D \\
(\mu \mathrm{g} / \mathrm{mL})\end{array}$ & $\begin{array}{l}\text { Precision } \\
\text { RSD (\%) }\end{array}$ & $\begin{array}{l}\text { Accuracy } \\
\text { (\%) }\end{array}$ & $\begin{array}{l}\text { LC }=\bar{x} \pm[t \\
\left.. S D /(n)^{1 / 2}\right] \\
(\mu g / m L)\end{array}$ \\
\hline \multirow{5}{*}{$\begin{array}{l}\text { Pitavastatin } \\
\text { calcium }\end{array}$} & 4.40 & 4.41 & 0.097 & 2.20 & 100.23 & $4.41 \pm 0.121$ \\
\hline & 8.80 & 8.85 & 0.151 & 1.71 & 100.57 & $8.85 \pm 0.188$ \\
\hline & 17.61 & 17.47 & 0.097 & 0.56 & 99.20 & $\begin{array}{ll}17.47 & \pm \\
0.121 & \end{array}$ \\
\hline & 26.42 & 27.07 & 0.174 & 0.64 & 102.46 & $\begin{array}{ll}27.07 & \pm \\
0.216 & \end{array}$ \\
\hline & 35.23 & 34.69 & 0.074 & 0.21 & 98.47 & $\begin{array}{ll}34.69 & \pm \\
0.092 & \end{array}$ \\
\hline
\end{tabular}

$\overline{\mathrm{x}}$ : mean of five replicated determinations, Accuracy $(\%)=$ (observed concentration/theoretical concentration) $\times 100$,

Precision $($ RSD \%) $=$ (standard deviation/mean concentration $) \times 100$.

LC: Limit of confidence at $95 \% ; t=2.78$.

\section{Precision}

In order to demonstrate the precision of the proposed method, intra-day and inter-day variability studies were performed at three different concentrations $(4.40,13.21$, and 22.02) $\mu \mathrm{g} / \mathrm{mL}$ for Pitavastatin Calcium at the same day in two hour's time interval and also at three different days. Method efficiency was tested in terms of RSD \% for both intra-day and inter-day precisions.

The precision was ascertained by carrying out five replicates of standard Pitavastatin calcium under study and the mean was calculated. The results are showed in Table 2 . The RSD \% results were not more than $2.91 \%$ during the determination in one day or three days, where the method is considered very precise.

Table 2: Intra-day and inter-day precision for determination of Pitavastatin calcium.

\begin{tabular}{|l|l|l|}
\hline Intra-day \\
\hline Sample & Concentration & Found concentration $\mu \mathrm{g} / \mathrm{mL}$ \\
\hline
\end{tabular}




\begin{tabular}{|c|c|c|c|c|c|c|c|}
\hline & $\mu \mathrm{g} / \mathrm{mL}$ & * Time & $\begin{array}{r}\text { Precision } \\
\text { RSD\% }\end{array}$ & $\begin{array}{c}\text { * Time } \\
\text { II }\end{array}$ & $\begin{array}{r}\text { Precision } \\
\text { RSD \% }\end{array}$ & $\begin{array}{ll}\text { * Time } & \text { Til } \\
\text { III } & \end{array}$ & $\begin{array}{r}\text { Precision } \\
\text { RSD\% }\end{array}$ \\
\hline \multirow{3}{*}{$\begin{array}{l}\text { Pitavastatin } \\
\text { calcium }\end{array}$} & 4.40 & 4.43 & 1.98 & 4.41 & 2.53 & 4.41 & 2.75 \\
\hline & 13.21 & 13.44 & 1.35 & 13.40 & 1.15 & 13.43 & 0.81 \\
\hline & 22.02 & 21.89 & 0.79 & 22.07 & 1.95 & 21.93 & 0.83 \\
\hline \multicolumn{8}{|l|}{ Inter-day } \\
\hline \multirow[b]{2}{*}{ Sample } & \multirow{2}{*}{$\begin{array}{r}\text { concentration } \\
\mu \mathrm{g} / \mathrm{mL}\end{array}$} & \multicolumn{6}{|c|}{ Found Concentration $\mu \mathrm{g} / \mathrm{mL}$} \\
\hline & & * Day I & $\begin{array}{r}\text { Precision } \\
\text { RSD\% }\end{array}$ & *Day II & $\begin{array}{r}\text { Precision } \\
\text { RSD \% }\end{array}$ & *Day III & $\begin{array}{r}\text { Precision } \\
\text { RSD\% }\end{array}$ \\
\hline \multirow{3}{*}{$\begin{array}{l}\text { Pitavastatin } \\
\text { Calcium }\end{array}$} & 4.40 & 4.41 & 2.42 & 4.41 & 2.91 & 4.42 & 2.21 \\
\hline & 13.21 & 13.42 & 1.10 & 13.51 & 0.91 & 13.45 & 0.71 \\
\hline & 22.02 & 21.69 & 1.19 & 22.01 & 1.09 & 22.05 & 2.39 \\
\hline
\end{tabular}

${ }^{*} \mathrm{n}=5$.

\section{Robustness}

The robustness of an analytical procedure is a measure of its capacity to maintain unaffected results by a very small variation of some parameters and provides an indication of its reliability during normal usage. The studied variables parameters were slit scan speed and the wavelength, which performed at concentration $(13.21 \mu \mathrm{g} / \mathrm{mL})$ for Pitavastatin calcium Table 3.

Table 3: Robustness test.

\begin{tabular}{|l|l|l|l|l|l|}
\hline Initial conditions & Measured deviation & $\begin{array}{c}\bar{x}^{*} \\
\mathbf{\mu g} / \mathbf{m L}\end{array}$ & $\begin{array}{l}\mathbf{S D} \\
\mathbf{\mu g} / \mathbf{m L}\end{array}$ & $\begin{array}{l}\text { RSD } \\
\%\end{array}$ & Percent (\%) \\
\hline Step size & $\mathbf{0 . 5} \mathbf{~ n m}$ & 13.43 & 0.22 & 1.64 & 101.67 \\
$\mathbf{1} \mathbf{~ n m}$ & $\mathbf{2} \mathbf{~ n m}$ & 13.48 & 0.12 & 0.89 & 102.04 \\
\hline \multirow{2}{*}{ Scan speed medium } & Fast & 13.24 & 0.27 & 2.04 & 100.23 \\
& $\mathbf{S l o w}$ & 13.33 & 0.24 & 1.80 & 100.91 \\
\hline Wavelength & $\mathbf{+ 2} \mathbf{~ n m}$ & 13.36 & 0.25 & 1.87 & 101.14 \\
$\mathbf{4 0 5} \mathbf{~ n m}$ & $\mathbf{- 2} \mathbf{~ n m}$ & 13.29 & 0.25 & 1.88 & 100.61 \\
\hline
\end{tabular}

${ }^{*} \mathrm{n}=5$.

\section{Sensitivity Sandell's and molar absorptivity}

Sensitivity of the proposed method for Pitavastatin Calcium was determined by calculating Sandell's sensitivity (SS), it was to be SS $=0.0259 \mu \mathrm{g} / \mathrm{cm}^{2}$. The mean molar absorptivity $\varepsilon$ was found equal to $67830.11 \mathrm{~L} / \mathrm{mol} . \mathrm{cm}$.

\section{Recovery}

The recovery was studied by three addition standards ( $80 \%, 100 \%$, and $120 \%)$ for every product.

Table 4 presents the recoveries results for the two Syrian products (PAVACORIUM 4 and Londalop). 
Table 4: Recoveries of Pitavastatin Calcium in PAVACORIUM 4 and Londalop.

\begin{tabular}{|c|c|c|c|c|c|c|c|c|}
\hline Products & $\begin{array}{l}\text { Pharmaceutical } \\
\text { dosage }\end{array}$ & $\begin{array}{l}\text { Sample } \\
\mu \mathrm{g} / \mathrm{mL}\end{array}$ & $\begin{array}{l}\text { Added } \\
\mu \mathrm{g} / \mathrm{mL}\end{array}$ & $\begin{array}{l}\text { Total } \\
\text { Found } \\
\bar{x} \\
\mu \mathrm{g} / \mathrm{mL}\end{array}$ & $\begin{array}{l}\text { Recovery } \\
\text { Average } \\
\%\end{array}$ & $\begin{array}{l}\text { SD } \\
\mu \mathrm{g} / \mathrm{mL}\end{array}$ & RSD\% & $\begin{array}{l}\text { Recovery } \\
\text { Average } \\
\%\end{array}$ \\
\hline \multirow{3}{*}{$\begin{array}{l}\text { PAVACORIUM } \\
4\end{array}$} & \multirow{3}{*}{$\begin{array}{l}\text { Pitavastatin } \\
\text { Calcium } \\
4 \mathrm{mg} / \mathrm{tab} \text {. }\end{array}$} & \multirow{3}{*}{4.00} & 3.20 & 7.19 & 99.69 & 3.60 & 3.61 & \multirow{3}{*}{100.92} \\
\hline & & & 4.00 & 8.04 & 101.00 & 2.57 & 2.54 & \\
\hline & & & 4.80 & 8.90 & 102.08 & 1.70 & 1.67 & \\
\hline \multirow{3}{*}{ Londalop } & \multirow{3}{*}{$\begin{array}{l}\text { Pitavastatin } \\
\text { Calcium } \\
4 \mathrm{mg} / \mathrm{tab} \text {. }\end{array}$} & \multirow{3}{*}{4.00} & 3.20 & 7.28 & 102.50 & 4.03 & 3.93 & \multirow{3}{*}{101.14} \\
\hline & & & 4.00 & 8.02 & 100.50 & 3.23 & 3.21 & \\
\hline & & & 4.80 & 8.82 & 100.42 & 2.81 & 2.80 & \\
\hline
\end{tabular}

$\overline{\mathrm{x}}$ Means five separated determinations.

\section{APPLICATION}

\section{Estimation of Pitavastatin Calcium in PAVACORIUM 4 and Londalop products}

The developed method was applied for quantitative determination and identification Pitavastatin Calcium in two Syrian pharmaceutical products (PAVACORIUM 4 and Londalop) for three different batches for each one. The samples were prepared as described in the section of samples preparation and analyzed. Quantitative analysis was done by using calibration curve. The obtained results are summarized in table 5 . In general, the concentrations of the detected Pitavastatin Calcium compounds in the two products were within the allowed limits under USP legislation ${ }^{26}$, The tablets must contain not less than $90.00 \%$ and not more than $110.00 \%$ of labeled amount. So the obtained results are conformed to USP legislation ${ }^{26}$. The relative standard deviations RSD \% $(n=5)$ of the quantitative results were in the range of $0.80-2.90 \%$ for PAVACORIUM 4 and $2.59-3.41 \%$ for Londalop.

Table 5: Results of Pitavastatin Calcium in (PAVACORIUM 4 and Londalop) tablets.

\begin{tabular}{|l|l|l|l|}
\hline Product & \multicolumn{3}{|l|}{ PAVACORIUM 4 mg/tab. } \\
\hline Number of batch & $\mathbf{1}$ & $\mathbf{2}$ & $\mathbf{3}$ \\
\hline $\begin{array}{r}\text { Concentration } \\
\bar{x} \mathbf{~ m g / t a b .}\end{array}$ & 4.001 & 4.030 & 4.101 \\
\hline Range mg/tab. & $4.001-4.101$ \\
\hline SD mg/tab. & 0.032 & 0.093 & 0.119 \\
\hline RSD \% & 0.80 & 2.31 & 2.90 \\
\hline Range RSD \% & $0.80-2.90$ & 102.53 \\
\hline $\begin{array}{l}\text { Per \% } \\
100.03\end{array}$ & 100.75 & $100.03-102.53$ \\
\hline $\begin{array}{l}\text { Range Per \% } \\
\text { Londalop 4 mg/tab. }\end{array}$ \\
\hline $\begin{array}{l}\text { Product } \\
\text { Concentration } \\
\bar{x} \text { mg/tab. }\end{array} 4.01$ & 4.11 & 4.03 \\
\hline Range mg/tab. & \multicolumn{4}{|l|}{$4.01-4.11$} \\
\hline
\end{tabular}




\begin{tabular}{|l|l|l|l|}
\hline SD mg/vial & 0.104 & 0.140 & 0.127 \\
\hline RSD \% & 2.59 & 3.41 & 3.15 \\
\hline Range RSD \% & $2.59-3.41$ \\
\hline Per \% & 100.25 & 102.75 & 100.75 \\
\hline Range Per \% & \multicolumn{3}{|l}{$100.25-102.75$} \\
\hline
\end{tabular}

$\bar{x}$ Mean for five replicates.

\section{CONCLUSION}

We developed a new method which is suitable for the identification and quantification of Pitavastatin Calcium in raw material and Syrian tablets formulation. A good percentage of recovery shows that the method can be successfully used in pharmaceutical quality control and routine analyses. The proposed method is simple, sensitive, rapid, specific, a little cost. It could be applied for quality control of Pitavastatin Calcium in pharmaceutical factories. The levels of Pitavastatin Calcium compounds in the analyzed preparations were found to be within the permissible limits set by the USP legislation ${ }^{26}$.

\section{ACKNOWLEDGEMENT}

The Ministry of High Education in Syria financially and technically supported this work through department of Chemistry, Faculty of Science, University of Aleppo, Syria.

\section{REFERENCES}

1. S. Pitavastatin Approved for Treatment of Primary Hypercholesterolemia and Combined Dyslipidemia, Vascular Health and Risk Management. 2010:6, 997-1005.

2. Yasushi S, Nobuhiro Y, Tamio T, Hiroshige I, Yoshiya H, Noriaki N, Hiroshi M, Motoo T, Jun S, and Nobuya O. Clinical Efficacy of Pitavastatin, a New 3-Hydroxy-3-methylglutaryl Coenzyme A Reductase Inhibitor in Patients with Hyperlipidemia, Arzneim.- Forsch./Drug Res. 52, No. 4, 251-255.(2002)

3. MUKHTAR J. REID, J. Pitavastatin, Blackwell Publishing International Journal Clin Pract, February 2005, $59,2,239-252$.

4. Toshio H, Koutaro Y, Yasushi S, Akihisa I. Pitavastatin: Efficacy and Safety In Intensive Lipid Lowering, Pharmacother. (2007) 8 (14).

5. Jun Pankaj K, Bharti M, Satbir S. Pitavastatin: A Potent Drug, International Journal of Pharma Research and Health Sciences.2018;6 (1):2070-74.

6. Marwa K, Jamal L. Validated Kinetic Spectrophotometric Determination of Pitavastatin Calcium Using Acidic Permanganate Oxidation, Int J Pharm Pharm Sci, Vol 12, Issue 3, 28-33.

7. Niranjani S, Venkatachalam K. Method Development and Validation of Pitavastatin Calcium and its Degradation Behavior Under Varied Stress Conditions by UV Spectrophotometric Methods, Dhaka Univ. J. Pharm. Sci. 18(2): 159-169, 2019 (December).

8. Vadia N, Vandana P, Bhalara H. Spectrophotometric Determination of Cefetamet Pivoxil Hydrochloride and Pitavastatin Calcium in Tablet Dosage form, Indian Journal of Pharmaceutical Sciences.

9. Marothu V, Dannana G, Sankar. Adaptation of Color Reactions for Spectrophotometric Determination of Pitavastatin Calcium in Bulk Drugs and in Pharmaceutical Formulations Journal of Chemistry, Vol. 4, No.2, pp 272-278, April 2007.

10. Gamze E, Sena C, GLAR A, Arma G, Sidıka E. Spectrophotometric Determination of 3-Hydroxy-3Methylglutaryl Coenzyme-A Reductase Inhibitors in Pharmaceutical Preparations, Turk J Chem (2013) 37: $171-181$. 
11. Ramzia I, El-Bagary, Ehab F, ElKady M. Spectrofluorometric Determination of Certain Antihyperlipidemic Agents in Bulk and Pharmaceutical Preparations, Hindawi Publishing Corporation Spectroscopy: An International Journal Volume 27 (2012), Issue 2, Pages 83-92.

12. Ashok H. Akabari , Dinesh R. Shah, Shailesh A. Shah, Bhanubhai N. Suhagia, Kinetic Determinations of Pitavastatin Calcium by Stability Indicating HPTLC Method, Journal of Liquid Chromatography and Related Technologies, 38: 521-531, 2015.

13. Mrinalini C, Anuradha R. Stability Indicating HPTLC Method for the Estimation of Pitavastatin Calcium in presence of Acid Induced Degradation Product, International Journal of ChemTech Research. 2014,6(5),pp 2824-283.

14. Nanjappan S, Narayanan N, Jayabalan N, Narayanan S. HPLC Determination of Pitavastatin Calcium in Pharmaceutical Dosage Forms, Pharm Anal Acta 2:119.

15. Panchal H, Suhagia B. Stability-Indicating Liquid Chromatographic Method for Analysis of Pitavastatin Calcium in Tablet Dosage Forms, Acta Chromatographica 23(2011)1, 81-94.

16. Bozhanov S, Maslarska V. Spectroscopic and High-Performance Liquid Chromatography Methods for Determination of Statins, Pharmacia, vol. 63, No. 2/2016.

17. Hariram B, Kumar R, Anireddy J, Dama V, Kalyanaraman L, Katkam S. Ultra-High Performance Method on Superficially Porous Stationary Phase for the Determination of Related Substances in Pitavastatin Calcium by HPL, Springer-Verlag Berlin Heidelberg 2015.

18. Tirumala K, Gautam S, Gangadhar J, Jayajeevitha M, Prakask V. RP-HPLC Assay for Estimation of Pitavastatin in Bulk and Pharmaceutical Dosage Forms, International Journal of Pharmaceutical Scienes and Nanotechnology. Vol 7; Issue 1. January - March 2014.

19. Vinodkumar R, Girish J, Ashim S, Girish S, Vijaykumar S. Development and Validation of RP-HPLC Method for Pitavastatin Calcium in Bulk and Formulation Using Experimental Design, Journal of Applied Pharmaceutical Science Vol. 9(10), pp 075-083, October, 2019.

20. Sujatha K, Seshagir N. A New Validated Stability-Indicating RP-HPLC Method for the Estimation of Pitavastatin in Tablet Dosage Forms. Pharmacy and analytical research vol-3(1) 2014.(74 -67)

21. Xiemin Q, Ding L, Aidomg W, Zhou N, Xiaolang D, Shailendra S. Simple LC-MS/MS Methods for Simultaneous Determination of Pitavastatin and its Lactone Metabolite in Human Plasma and Urine Involving A Procedure for Inhibiting the Conversion of Pitavastatin Lactone to Pitavastatin In Plasma and its Application to A Pharmacokinetic Study, Journal of Pharmaceutical and Biomedical Analysis 72 (2013) 8-15.

22. Tengrui Y, Qian L, Hui Z, Lirong Z, Hui L, Miao L, Meilan C, Wengang R. Lcems/MS Assay For Pitavastatin In Human Plasma and Subsequent Application To A Clinical Study In Healthy Chinese Volunteers, asian journal of pharmaceutical sciences 9 (2014) 348e355.

23. Kudige N, Kanakapura B, Madihalli S. Simple and Selective Spectrophotometric Determination of Ofloxacin in Pharmaceutical Formulations Using Two Sulphonphthalein Acid Dyes. Hindawi Publishing Corporation, 2013.

24. Amina A, Goudab A, El-Sheikh R, Zahran F. Spectrophotometric Determination of Gatifloxacin in Pure Form and in Pharmaceutical Formulation. Spectrochimica Acta Part A. 2007; (67): 1306-1312.

25. Britton H.T.S., Hydrogen lons, fourth ed., Chapman and Hall, 1952.

26. Pharmacopeia USP34 NF 292011. 